\title{
Drought-induced $\mathrm{ABA}, \mathrm{H}_{2} \mathrm{O}_{2}$ and $\mathrm{JA}$ positively regulate $C m C A D$ genes and lignin synthesis in melon stems
}

\author{
Wei Liu ${ }^{1,2 \dagger}$, Yun Jiang ${ }^{1 \dagger}$, Yazhong Jin ${ }^{3}$, Chenghui Wang ${ }^{1,4}$, Juan Yang ${ }^{1}$ and Hongyan Qi ${ }^{1 *}$
}

\begin{abstract}
Background: Cinnamyl alcohol dehydrogenase (CAD) is an important enzyme functions at the last step in lignin monomer synthesis pathway. Our previous work found that drought induced the expressions of CmCAD genes and promoted lignin biosynthesis in melon stems.

Results: Here we studied the effects of abscisic acid (ABA), hydrogen peroxide $\left(\mathrm{H}_{2} \mathrm{O}_{2}\right)$ and jasmonic acid $(J A)$ to $\mathrm{CmCADs}$ under drought stress. Results discovered that drought-induced $\mathrm{ABA}, \mathrm{H}_{2} \mathrm{O}_{2}$ and MeJA were prevented efficiently from increasing in melon stems pretreated with fluridone (Flu, ABA inhibitor), imidazole (Imi, $\mathrm{H}_{2} \mathrm{O}_{2}$ scavenger) and ibuprofen (Ibu, JA inhibitor). $\mathrm{ABA}$ and $\mathrm{H}_{2} \mathrm{O}_{2}$ are involved in the positive regulations to $\mathrm{CmCAD1}, 2,3$, and 5 , and $\mathrm{JA}$ is involved in the positive regulations to $\mathrm{C} M C A D 2,3$, and 5. According to the expression profiles of lignin biosynthesis genes, $\mathrm{ABA}, \mathrm{H}_{2} \mathrm{O}_{2}$ and MeJA all showed positive regulations to CMPAL2-like, CMPOD1-like, CMPOD2-like and CmLAC4-like. In addition, positive regulations were also observed with ABA to CMPAL1-like, CmC4H and CmCOMT, with $\mathrm{H}_{2} \mathrm{O}_{2}$ to CmPAL1-like, CmC4H, CmCCR and CmLAC17-like, and with JA to CmCCR, CmCOMT, CmLAC11-like and CmLAC17-like. As expected, the signal molecules positively regulated CAD activity and lignin biosynthesis under drought stress. Promoter::GUS assays not only further confirmed the regulations of the signal molecules to CmCAD1 3, but also revealed the important role of $C m C A D 3$ in lignin synthesis due to the strongest staining of CMCAD3 promoter::GUS.
\end{abstract}

Conclusions: $\mathrm{CmCADs}$ but $\mathrm{CmCAD4}$ are positively regulated by $\mathrm{ABA}, \mathrm{H}_{2} \mathrm{O}_{2}$ and JA under drought stress and participate in lignin synthesis.

Keywords: Oriental melon, Cinnamyl alcohol dehydrogenase, Drought, Lignin, Abscisic acid, Hydrogen peroxide, Jasmonic acid

\section{Background}

Lignin is the second rich substance in plants [1] and plays important roles in sap transport and water barrier in addition to the basal function of support [2]. In lignin

\footnotetext{
* Correspondence: qihongyan@syau.edu.cn; hyqiaaa@126.com

${ }^{\dagger}$ Wei Liu and Yun Jiang contributed equally to this work.

${ }^{1}$ Key Laboratory of Protected Horticulture of Education Ministry and Liaoning Province, College of Horticulture, Shenyang Agricultural University, National \& Local Joint Engineering Research Center of Northern Horticultural Facilities Design \& Application Technology (Liaoning), Shenyang 110866, Liaoning, People's Republic of China

Full list of author information is available at the end of the article
}

monomer synthesis pathway, cinnamyl alcohol dehydrogenase (CAD) is an important enzyme which functions in the last step responsible for the transformation between cinnamyl aldehydes and cinnamyl alcohols. Lignin synthesis is not only complied with regular growth, but also can be regulated by biotic and abiotic stresses. As one frequently happened abiotic stress, drought negatively affects plant growth but promotes lignification process. Some research showed that lignifying enzymes (cinnamoyl CoA reductase (CCR), CAD, kinds of peroxidases) were induced and lignin synthesis was promoted

(c) The Author(s). 2021 Open Access This article is licensed under a Creative Commons Attribution 4.0 International License, which permits use, sharing, adaptation, distribution and reproduction in any medium or format, as long as you give appropriate credit to the original author(s) and the source, provide a link to the Creative Commons licence, and indicate if changes were made. The images or other third party material in this article are included in the article's Creative Commons licence, unless indicated otherwise in a credit line to the material. If material is not included in the article's Creative Commons licence and your intended use is not permitted by statutory regulation or exceeds the permitted use, you will need to obtain permission directly from the copyright holder. To view a copy of this licence, visit http://creativecommons.org/licenses/by/4.0/ The Creative Commons Public Domain Dedication waiver (http://creativecommons.org/publicdomain/zero/1.0/) applies to the data made available in this article, unless otherwise stated in a credit line to the data. 
in shoots under drought stress [3-6]. While in roots, lignin biosynthesis was suppressed at the beginning and induced in the late period when suffering drought stress [7-9]. The positive promotion of drought on lignification may confer to plants drought tolerance in aspects of water transport [10] and water loss [11].

Drought-affected lignification is mainly regulated by stress-induced signal molecules, such as abscisic acid (ABA), hydrogen peroxide $\left(\mathrm{H}_{2} \mathrm{O}_{2}\right)$, jasmonic acid (JA), salicylic acid (SA), and etc. Previous studies reported that JA can induce $C A D$ gene expression [12] and promote lignin deposition together with reactive oxygen species (ROS) [13, 14]. $\mathrm{H}_{2} \mathrm{O}_{2}$ can control lignification not only in shoots with light [15], but also in roots without light [16]. While the regulation of ABA to lignification still remains controversial, Mohr and Cahill (2007) [17] reported that ABA inhibited lignin synthesis and SA accumulation in Arabidopsis leaves, however studies also found that ABA increased expressions of lignin biosynthesis genes (phenylalanine ammonia $(P A L)$, cinnamate 4hydroxylase $(C 4 H)$, 4-coumarate-CoA ligase (4CL5), $C A D, C C R$, ferulate 5-hydroxylase (F5H1)) and activities of lignifying enzymes (PAL, peroxidase (POD)), thus promoted the accumulation of lignin [18-20]. In addition, positive correlations were also observed between ABA, JA, SA and lignification in mature and senescence tissues [21, 22].

As an important enzyme in lignin monomer synthesis pathway, activity of CAD enzyme and expression levels of $C A D$ genes were promoted by drought and signal molecules, resulting in lignin deposition $[5,16,23]$. CAD genes usually present as a gene family in different species and each member may function distinctly or redundantly from each other [24, 25]. Our team discovered five $C m C A D$ genes in melon genome database (http:// melonomics.cragenomica.es/) [26] and found they can be significantly up-regulated by drought stress in melon seedlings [27]. However, it remains unclear which signal molecule is responsible for regulating CmCADs under drought stress.

In this study, we investigated the regulations of $A B A$, $\mathrm{H}_{2} \mathrm{O}_{2}$ and JA to the five $C m C A D$ genes, as well as some lignin biosynthesis genes, and lignin deposition through using their corresponding inhibitor or scavenger. Then promoter::GUS assays were performed to investigate the regulations of the signal molecules to $C m C A D 1,2$, and 3 , which members were chosen according to the phylogenetic analysis [26] and the expression profiles under drought stress [27], as well as the expression patterns in melon seedlings (unpublished data). The results revealed important roles of $\mathrm{ABA}, \mathrm{H}_{2} \mathrm{O}_{2}$ and $\mathrm{JA}$ in regulating CmCAD1 3, 5 and lignin biosynthesis genes, thus in regulating lignin biosynthesis under drought stress.

\section{Results}

Drought-induced $A B A, \mathrm{H}_{2} \mathrm{O}_{2}$ and MeJA could be inhibited by the corresponding inhibitor or scavenger

ABA and $\mathrm{H}_{2} \mathrm{O}_{2}$ are frequently reported as important signal molecules in regulating downstream gene expression and metabolism under drought stress $[6,28]$. While, it remains controversial of the role of JA under drought stress [29]. To investigate the changes of $\mathrm{ABA}, \mathrm{H}_{2} \mathrm{O}_{2}$ and JA in melon stems under drought stress, contents of ABA, $\mathrm{H}_{2} \mathrm{O}_{2}$ and JA were determined and found the signal molecules were all induced by PEG treatment (Fig. 1a-c). ABA and $\mathrm{H}_{2} \mathrm{O}_{2}$ responded to drought fast and reached peak value at $2 \mathrm{~h}$ (1.6 fold) and $3 \mathrm{~h}(2.26$ fold), respectively, while JA reached peak value at $7 \mathrm{~h}$ (1.54 fold) after PEG treatment. Though decreases were observed after reaching peak values, contents of the signal molecules still maintained higher levels than those in control.

Fluridone (Flu), imidazole (Imi) and ibuprofen (Ibu) are used as inhibitor or scavenger in investigating the functions of $\mathrm{ABA}, \mathrm{H}_{2} \mathrm{O}_{2}$ and JA in plants [30, 31]. Here, we evaluated the inhibitory efficiency of Flu, Imi and Ibu to $\mathrm{ABA}, \mathrm{H}_{2} \mathrm{O}_{2}$ and JA, respectively, in melon stems under drought stress. As shown in Fig. 1d-f, the signal molecules slightly decreased when treated with Flu, Imi or Ibu alone, showing 9.5, 7.5 and $11 \%$ decreases compared to those in control, respectively, but were significantly restricted from increasing in PEG-treated melon stems pretreated with Flu, Imi and Ibu, showing 26.4, 36.1 and $22.7 \%$ decreases compared to those in PEGtreated samples, respectively. Thus, they can also be used as effective inhibitor or scavenger in melon seedlings for further study.

\section{CmCADs were positively regulated by $A B A, \mathrm{H}_{2} \mathrm{O}_{2}$ and MeJA under drought}

The relationship between drought-induced CmCADs [27] and the signal molecules is investigated. As shown in Fig. 2, expression profiles of $C m C A D 1 \sim 5$ increased 4.2, 7.3, 10.3, 3.2, 5.6 fold, respectively, under PEG treatment. ABA treatment significantly up-regulated the expressions of CmCAD1 (2.8 fold), 2 (4.4 fold), 3 (5.2 fold), and 5 (2.8 fold), and Flu pretreatment significantly inhibited the upregulations of them in PEG-treated melon seedlings (2.2, $4.8,4.2,3.4$ fold, respectively). $\mathrm{H}_{2} \mathrm{O}_{2}$ treatment also significantly up-regulated the expressions of CmCAD1 (2.3 fold), 2 (5.5 fold), 3 (4.3 fold), and 5 (4.4 fold), and Imi pretreatment severely inhibited the up-regulations of them in PEG-treated melon seedlings $(2.5,2.6,5.3,2$ fold, respectively). MeJA treatment significantly up-regulated the expressions of CmCAD2 (6.8 fold), 3 (7.6 fold), and 5 (4.6 fold), and Ibu pretreatment strongly inhibited the upregulations of them in PEG-treated melon seedlings (2.8, 4.2, 1.9 fold, respectively). Notably, MeJA exhibited 


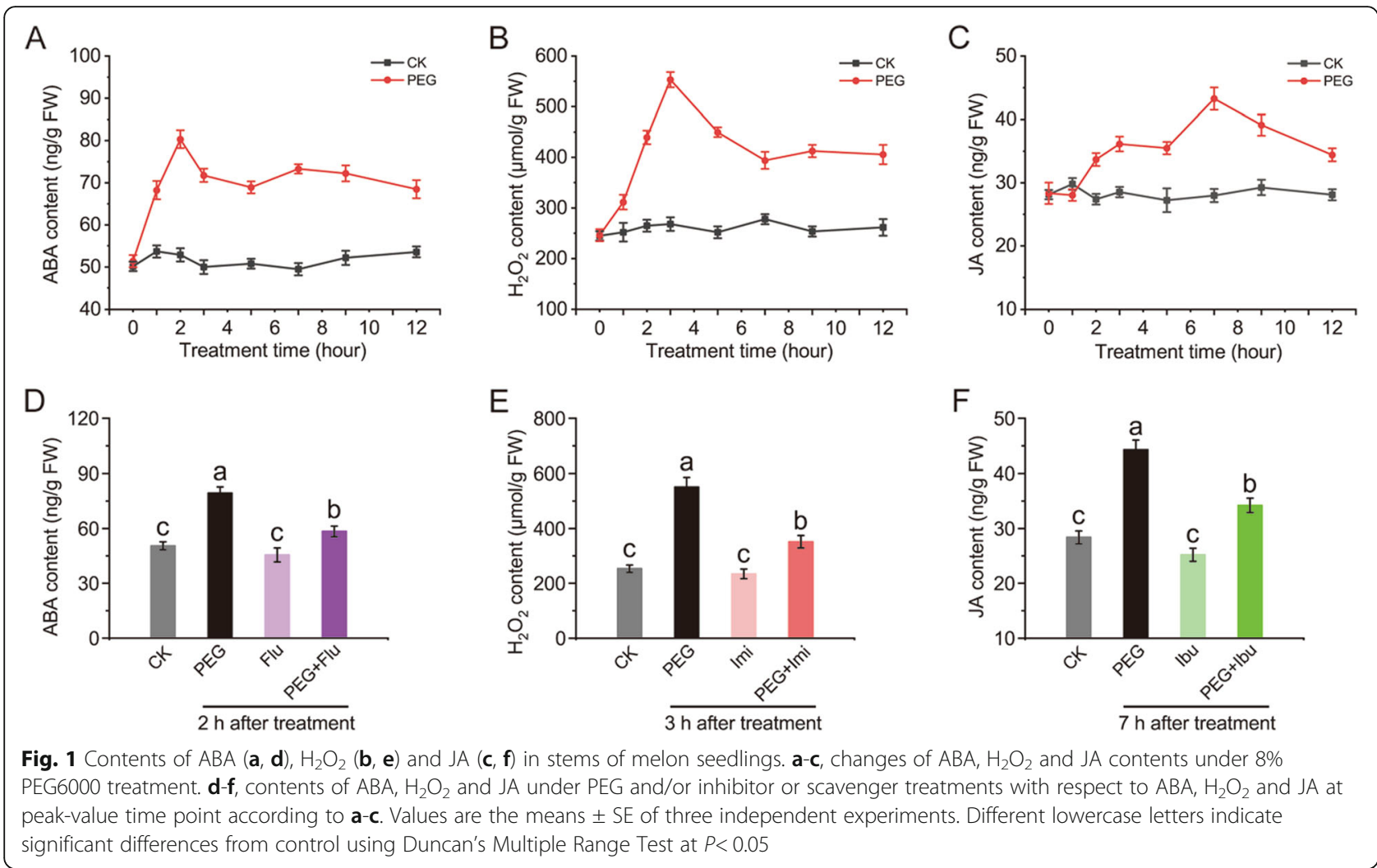

stronger regulations to $C m C A D 2$ and 3 than $A B A$ and $\mathrm{H}_{2} \mathrm{O}_{2}$ did. CmCAD4 was slightly regulated by the signal molecules. Treated with each inhibitor or scavenger alone had no or little effect on CmCADs expressions.

\section{Lignin biosynthesis genes were diversely regulated by $\mathrm{ABA}, \mathrm{H}_{2} \mathrm{O}_{2}$ and MeJA under drought}

Thereafter, we also investigated the expression profiles of some lignin biosynthesis genes in the lignin monomer synthesis pathway as shown in Fig. 3. CmC4H, Cm4CL, $C m C C R$ and caffeic acid $O$-methyltransferase (CmCOMT) were selected according to Jing et al. (2018) [32]. CmPAL1like, CmPAL2-like, CmPOD1-like, CmPOD2-like, laccase (CmLAC4-like, CmLAC11-like and CmLAC17-like) genes are highly homologous to the corresponding genes identified in lignin synthesis in Arabidopsis [33-35].

The lignin biosynthesis genes were all highly upregulated in expressions under drought stress. Among the genes, CmPAL1-like, CmPAL2-like, CmC4H, CmCOMT, CmPOD1-like, CmPOD2-like and CmLAC4-like were induced by $\mathrm{ABA}$ treatment and inhibited from increases under PEG+Flu treatment, indicating ABA signalling involves in the regulation of these genes. Similarly, CmPAL1like, CmPAL2-like, CmC4H, CmCCR, CmPOD1-like, CmPOD2-like, CmLAC4-like and CmLAC17-like were upregulated by $\mathrm{H}_{2} \mathrm{O}_{2}$ treatment and restricted from inductions under PEG+Imi treatment, suggesting the positive regulation of $\mathrm{H}_{2} \mathrm{O}_{2}$ to these genes. The lignin biosynthesis genes except for CmPAL1-like, $\mathrm{CmC4H}$ and $\mathrm{Cm} 4 \mathrm{CL}$ were induced by MeJA treatment and inhibited by PEG+Ibu treatment, implying JA signalling involves in the regulation of these genes. $\mathrm{Cm} 4 C L$ studied here was only slightly regulated by $\mathrm{H}_{2} \mathrm{O}_{2}$.

\section{CAD activity was positively regulated by $A B A, \mathrm{H}_{2} \mathrm{O}_{2}$ and MeJA under drought}

Since ABA, $\mathrm{H}_{2} \mathrm{O}_{2}$ and MeJA play positive roles in regulating the $C m C A D s$ under drought stress, it is necessary to investigate the effects of the signal molecules on CAD activity. Under various treatments, CAD activity was actively induced under PEG treatment and not affected by each inhibitor or scavenger treatment. Signal molecule treatments promoted CAD activity from increasing in melon stems and inhibitor or scavenger pretreatments inhibited CAD activity from increasing in PEG-treated melon stems (Fig. 4). Among the signal molecules, ABA induced $\mathrm{CAD}$ activity to significant levels (increased 6.4-15.2\%) (Fig. 4a), and MeJA promoted CAD activity from increasing about 4.9-17.9\% (Fig. 4c), while $\mathrm{H}_{2} \mathrm{O}_{2}$ showed slight induction to CAD activity which only reached significant level (7\%) at 3 day after treatment (Fig. 4b). Pretreatments of inhibitor or scavenger all strongly suppressed the up-regulation of CAD activity in PEG-treated melon stems. These results suggest that the 

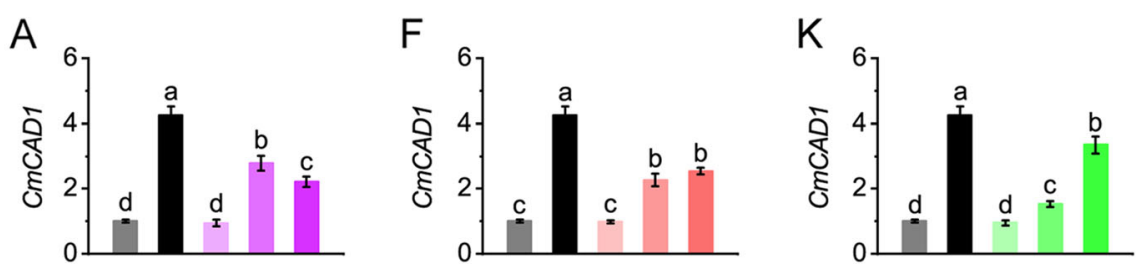

B
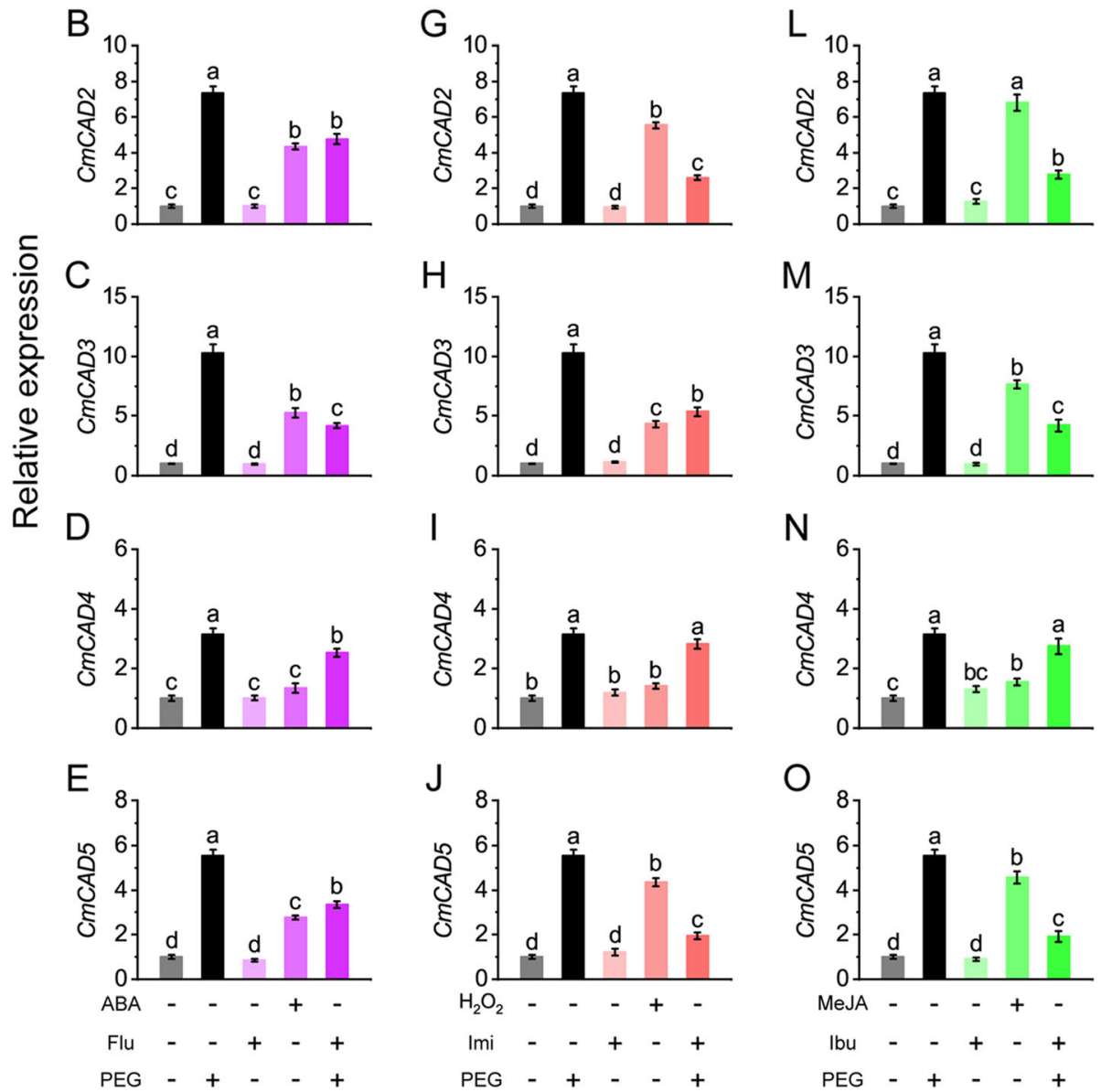

Fig. 2 qRT-PCR analysis the relative expressions of $C m C A D$ genes in stems of melon seedlings regulated by $A B A(\mathbf{a}-\mathbf{e}), \mathrm{H}_{2} \mathrm{O}_{2}(\mathbf{f}-\mathbf{j})$ and $M e J A(\mathbf{k}-\mathbf{o})$. Values are the means \pm SE of three independent experiments. Different lowercase letters indicate significant differences from control using Duncan's Multiple Range Test $(P<0.05)$

signal molecules probably involves in the up-regulation of CAD activity by PEG treatment.

\section{Lignin biosynthesis was positively regulated by $A B A$, $\mathrm{H}_{2} \mathrm{O}_{2}$ and $\mathrm{MeJA}$ under drought}

Further, assays of lignin content and histochemical staining were performed. Results as shown in Fig. 5, lignin biosynthesis in stems was significantly promoted by PEG treatment and inhibited by inhibitor or scavenger pretreatments. Though not to significant levels, the signal molecule treatments showed slight promotions on lignin biosynthesis and deposition in similar patterns (Fig. 5a, c, e). Histochemical staining with phloroglucinol- $\mathrm{HCl}$ is a method commonly used for direct lignin observation.
Consistent with lignin content detection, xylem tissues in vascular bundles exhibited the strongest staining under PEG treatment, the modest staining under treatments of the signal molecules or pretreatments of inhibitor or scavenger, and the control-like staining under treatments of inhibitor or scavenger (Fig. 5b, d, f). These results suggest that the signal molecules play positive roles in lignin biosynthesis under drought stress.

\section{Promoters of $C m C A D 1,2$, and 3 were positively induced by $\mathrm{ABA}, \mathrm{H}_{2} \mathrm{O}_{2}$ and MeJA}

To further study the response of $C m C A D s$ to the three signal molecules, we constructed promoter::GUS vectors of CmCAD1 pro::GUS, CmCAD2 pro::GUS and 


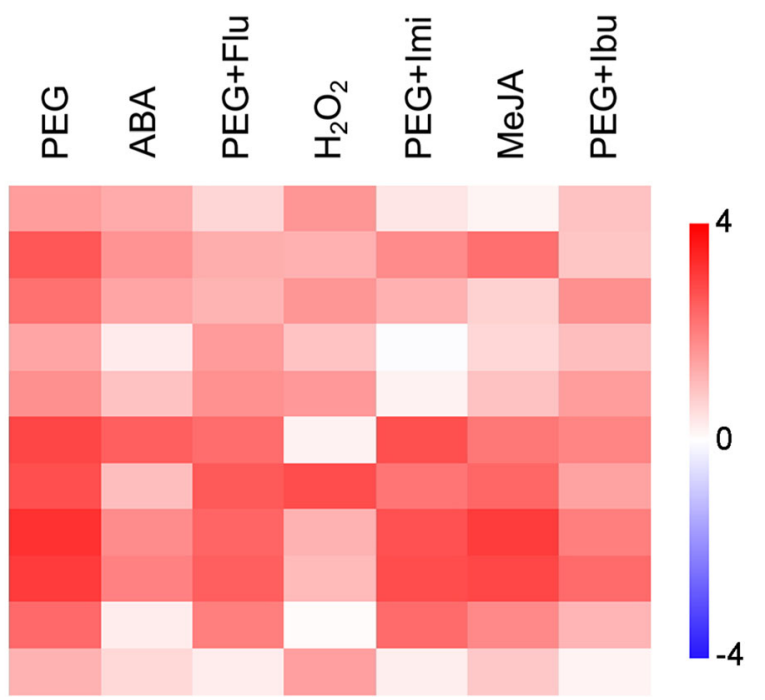

Fig. 3 Heat map depicting expression fold changes of lignin biosynthesis genes in lignin monomer synthesis pathway. Data presented as $\log _{2}$ [abundance in sample/abundance in control]. Data are collected from biological replicates $(n=3)$

CmCAD3 pro::GUS and carried out GUS assays in tobacco leaves treated with $\mathrm{ABA}(100 \mu \mathrm{M}), \mathrm{H}_{2} \mathrm{O}_{2}(10 \mathrm{mM})$ or MeJA $(100 \mu \mathrm{M})$. As Fig. 6a revealed, positive control showed the strongest GUS staining driven by $35 \mathrm{~S}$ promoter and negative control exhibited no GUS staining without promoter. Under control, CAD1 pro::GUS had the slightest GUS staining, CAD2 pro::GUS the modest, and CAD3 pro::GUS the strongest which is consistent with its highest expression pattern in melon seedlings. Under signal molecule treatments, CmCAD1 pro::GUS was slightly induced by MeJA, but was strongly induced by $\mathrm{ABA}$ and $\mathrm{H}_{2} \mathrm{O}_{2}$. While CmCAD2 pro::GUS and CmCAD3 pro::GUS exhibited similar staining patterns, they were both slightly induced by ABA and strongly induced by $\mathrm{H}_{2} \mathrm{O}_{2}$ and MeJA. GUS activity assay, Fig. 6b, obtained similar results with those of histochemical staining. GUS activity driven by $C m C A D 1$ promoter increased 9.7, 15.9 and 4.6 fold in response to $\mathrm{ABA}, \mathrm{H}_{2} \mathrm{O}_{2}$ and MeJA, respectively. GUS activity driven by $\mathrm{CmCAD} 2$ promoter observed 1.5, 1.9 and 2.2 fold increases in response to $\mathrm{ABA}, \mathrm{H}_{2} \mathrm{O}_{2}$ and MeJA, respectively. And 1.2, 1.6 and 1.7 fold increases of GUS activity were observed driven by $C m C A D 3$ promoter in response to $\mathrm{ABA}, \mathrm{H}_{2} \mathrm{O}_{2}$ and MeJA, respectively. These results demonstrate that the signal molecules play important roles in regulating $C m C A D 1,2$, and 3.

\section{Discussion}

Jin et al. (2014) [26] analyzed the promoters of the five $C m C A D$ genes and discovered elements responsible for ABA, $\mathrm{H}_{2} \mathrm{O}_{2}$, JA, stresses and etc. In plants, $\mathrm{ABA}, \mathrm{H}_{2} \mathrm{O}_{2}$ and JA are very important signal molecules responsible for plant growth regulation under either normal condition or stressful conditions [36-38]. Drought, as a frequently encountered abiotic stress, usually induce ABA, $\mathrm{H}_{2} \mathrm{O}_{2}$ and JA from highly increasing [6, 39], however, these signal molecules regulate lignification diversely in different species $[14,17,20,40]$. Thus it becomes necessary to reveal the regulating patterns of these signal molecules to $C m C A D$ genes as well as lignification in melon stems under drought stress for adding an understanding.

First of all, we confirmed that $\mathrm{ABA}, \mathrm{H}_{2} \mathrm{O}_{2}$ and JA all could be induced significantly by drought stress and reached peak values differentially after PEG treatment, and then they were efficiently restricted from reaching each peak value pretreated with inhibitor or scavenger, implying their signalling to downstream can be weakened efficiently. While, treated with inhibitor or scavenger alone had little effect on the signal molecules as well as thereafter indexes, which is similar with the results observed by Hu et al. (2013), Kojo et al. (2006) and Shan and Liang (2010) [30, 41, 42]. The inhibitor or scavenger exhibited little effect on the signal molecules when treated with each of them alone, but strongly inhibited the singal molecules from increasing under PEG+inhibitor or +scavenger treatments, which can be explained that they do nothing with the existed signal molecules but strongly inhibit the synthesis and accumulation of the signal molecules induced by PEG treatment.

Application of inhibitor or scavenger revealed that ABA and $\mathrm{H}_{2} \mathrm{O}_{2}$ exhibited similar positive regulations to CmCAD1, 2, 3, and 5. While, JA showed more direct regulations to $C m C A D 2$ and 3, as well as $C m C A D 5$, and exhibited slight regulation to $C m C A D 1$. $C m C A D 4$ was slightly affected by the signal molecules. This is 

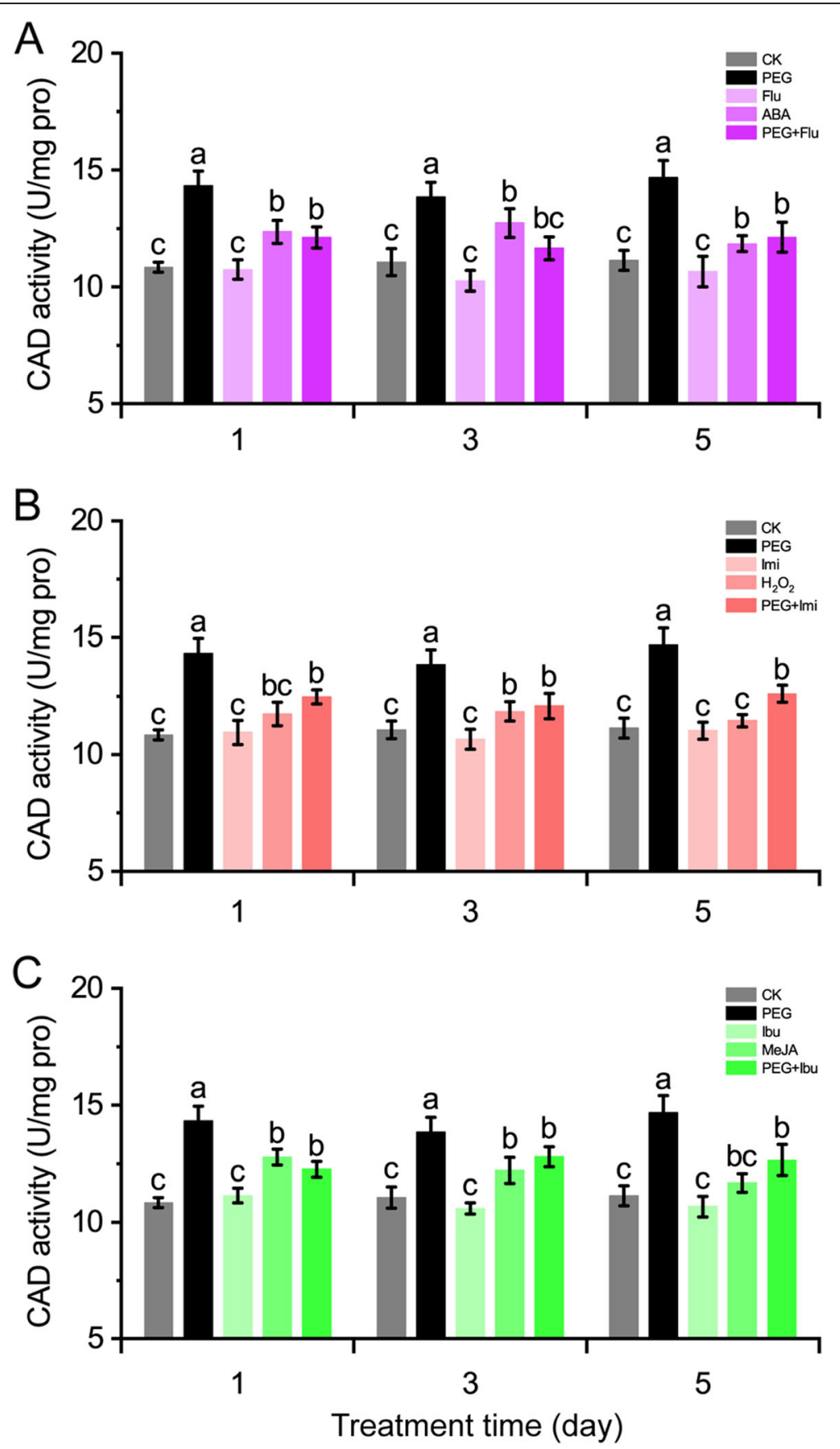

Fig. 4 Effects of pretreated with $A B A$ inhibitor fluridone (a), $\mathrm{H}_{2} \mathrm{O}_{2}$ scavenger imidazol (b) and MeJA inhibitor ibuprofen (c) on CAD activity in stems of melon seedlings exposed to PEG. Values are the means \pm SE of three independent experiments. Different lowercase letters indicate significant differences from control using Duncan's Multiple Range Test $(P<0.05)$

consistent with previous $C m C A D s$ promoter analysis [26]. In the $1.5 \mathrm{~kb}$ promoter sequences of $C m C A D s$, promoters of $C m C A D 1,2$, and 5 contain TC-rich repeats (cis-acting element involved in defense and stress responsiveness) which may drive the genes responding to $\mathrm{H}_{2} \mathrm{O}_{2}$. Promoters of $C m C A D 1,2,3$, and 5 contain ABRE element (cis-acting element involved in the abscisic acid responsiveness), and we demonstrated these $C m C A D s$ can be regulated by ABA. CmCAD3 promoter contains TGACG-motif and CCAAT-box and CmCAD5 promoter contains CGTCA-motif, all these three elements act as cis-acting regulatory elements involved in the MeJA-responsiveness, which were also confirmed in this study. In addition, some other stress- and signal- 


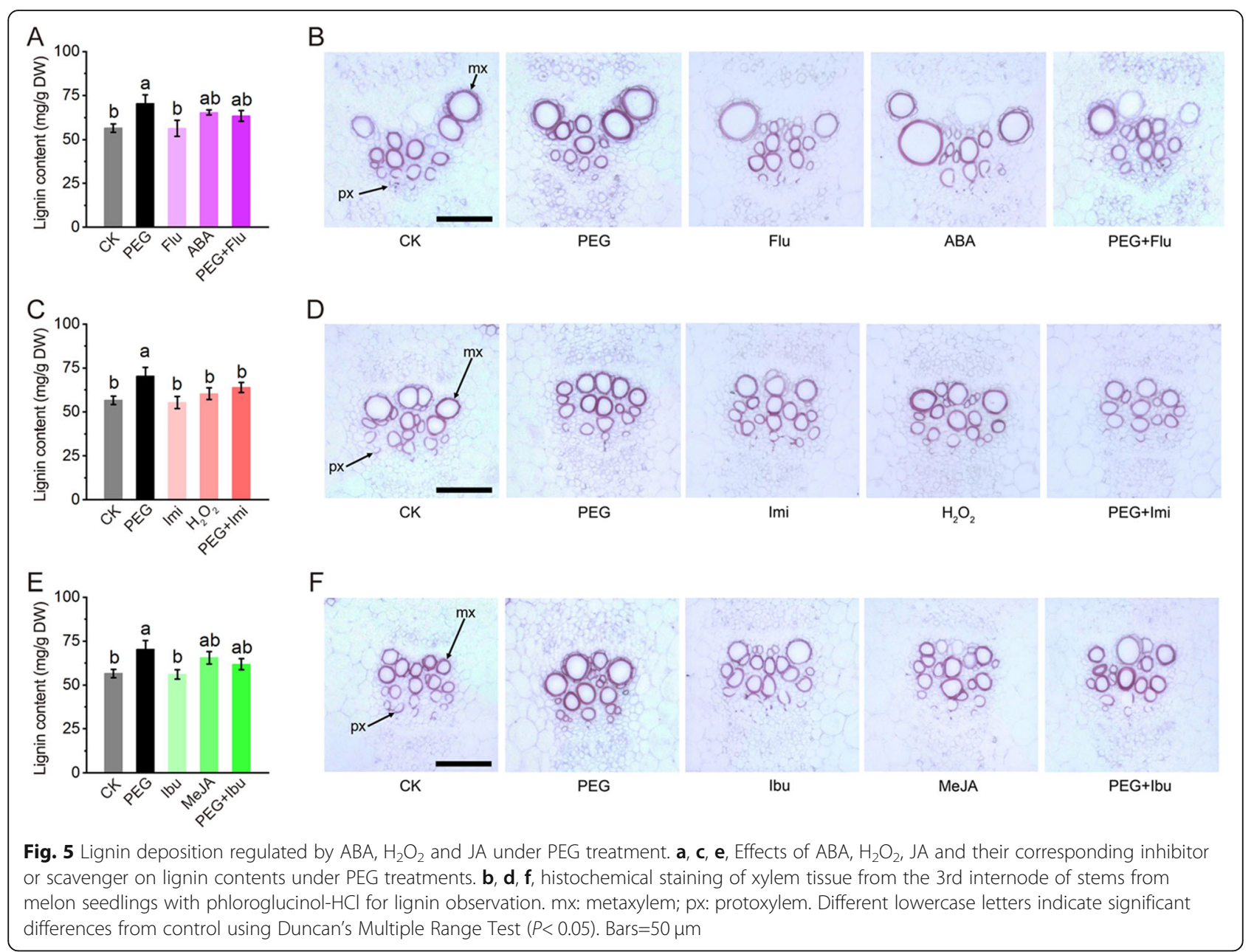

responding elements discovered in $C m C A D$ promoters ([26], Table S1) may be a reason why certain increases were still observed in PEG-treated melon seedlings pretreated with inhibitor or scavenger. The positive regulating patterns of the signal molecules to $C m C A D s$ are consistent with previous reports that one $C A D$ gene can be regulated by several signal molecules $[19,43]$ and different $C A D$ members in a family may respond to signal molecules and stresses differentially due to the distinct function each member fulfilled [24, 44]. Expression analysis of lignin biosynthesis genes further confirmed the positive regulations of ABA, $\mathrm{H}_{2} \mathrm{O}_{2}$ and JA to lignin biosynthesis under drought stress. Taken together, these results once again demonstrated that drought mediates gene expression depending on various signal molecules $[8,9,45]$.

CAD activity and lignin content was drastically induced by drought stress and slightly induced by signal molecule and PEG+inhibitor or +scavenger treatments. Slight inductions to CAD activity and lignin content by exogenous applications of signal molecules may due to the absorption efficiency as well as time-based effects of exogenous applied signal molecules. While the certain increases of CAD activity and lignin content under PEG+inhibitor or +scavenger treatments may due to the inhibitory efficiency of the inhibitors and scavenger, or exist bypass signalling pathways. These suggest a positive correlation between the signal molecules and CAD activity, resulting in lignin accumulation, which is consistent with previous reports [6]. Among the signal molecules, ABA and $\mathrm{H}_{2} \mathrm{O}_{2}$ showed similar regulations to CmCAD genes, but $\mathrm{ABA}$ and JA showed similar regulations to CAD activity and lignin deposition. However, Mohr and Cahill (2007) [17] presented an inverse result declaring a negative correlation between ABA and lignin, this may due to the reason that JA and SA are more likely responsible for lignin biosynthesis under biotic stresses [46, 47]. Antagonism and cooperation were both observed between ABA and JA under biotic stress [48, 49], which mechanism between ABA and JA interactions is considered existing both dependent and independent ways [38].

JA is also an important drought-response signal [42, 50] and functions in regulating lignin biosynthesis [21, 

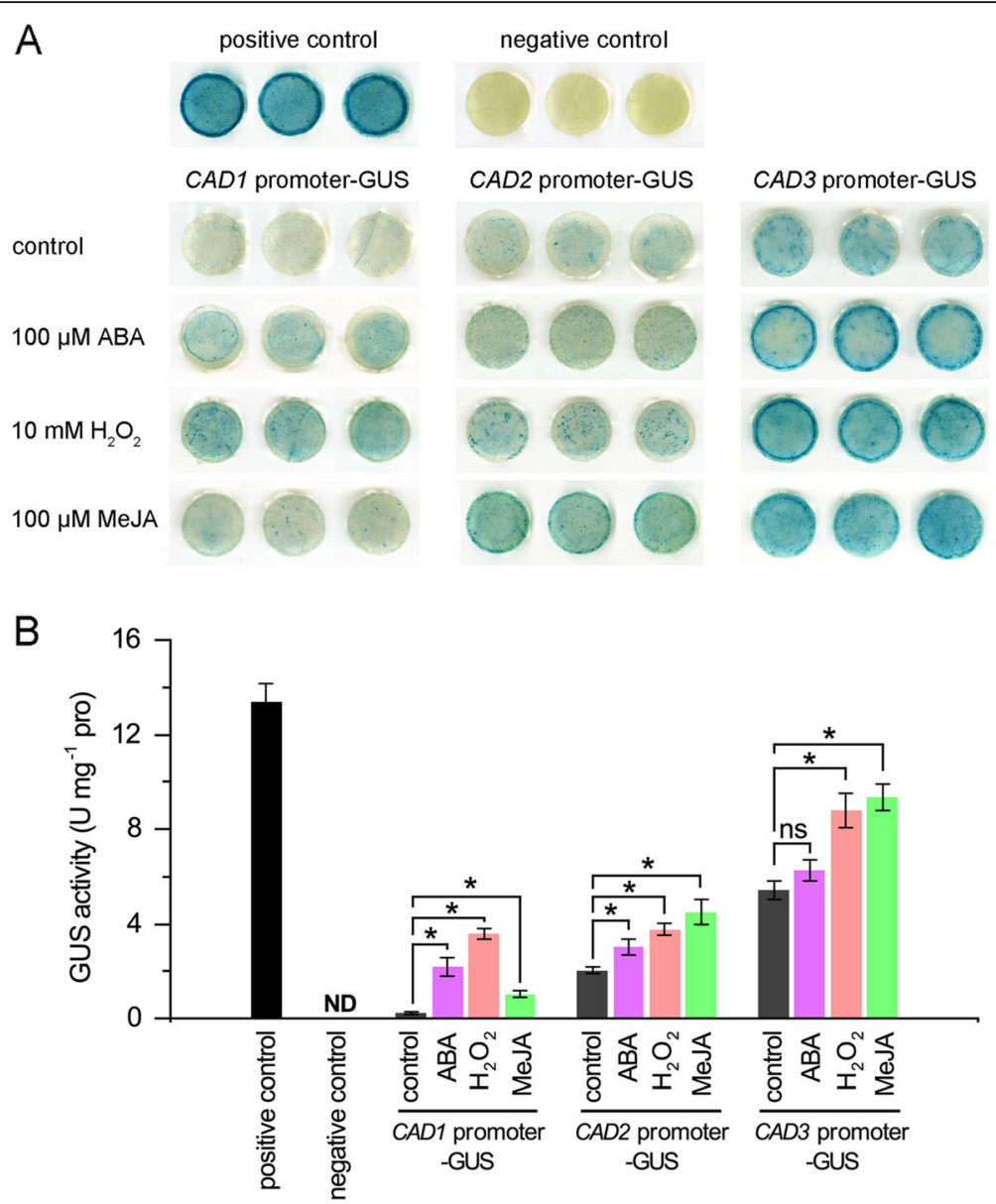

Fig. 6 Histochemical staining (a) and activity detection (b) of GUS driven by promoters with respect to $C m C A D 1-3$ treated with $A B A, \mathrm{H}_{2} \mathrm{O}_{2}$ and MeJA. Different lowercase letters indicate significant differences from control using Duncan's Multiple Range Test $(P<0.05)$. ND: not detected; ns: no significance

51]. Our results proved JA functions actively in promoting lignin biosynthesis in drought-stressed melon stems, which is similarly observed in Arabidopsis [40]. Previous studies on $\mathrm{H}_{2} \mathrm{O}_{2}$ also reported positive regulations to lignification showing that increased $\mathrm{H}_{2} \mathrm{O}_{2}$ content corresponded with higher lignin deposition [52] and decreased $\mathrm{H}_{2} \mathrm{O}_{2}$ content correlated with lower lignin deposition [16]. Consistently, our study also observed positive regulations of $\mathrm{H}_{2} \mathrm{O}_{2}$ to $C m C A D$ genes and $C A D$ activity, as well as lignification, in a slight degree which may due to the short lifespan of exogenous applied $\mathrm{H}_{2} \mathrm{O}_{2}$.

Earlier, Jin et al. (2014) [26] analyzed and discovered stress and signal response elements in the promoters of CmCAD genes, and later, Liu et al. (2018) [27] revealed that drought could induce $C m C A D s$ expressions and promote lignin deposition. As the signal molecule and inhibitor or scavenger treatments revealed in this study, $C m C A D s$ are positively regulated by $\mathrm{ABA}, \mathrm{H}_{2} \mathrm{O}_{2}$ and JA. To further demonstrate the regulating patterns, promoter::GUS constructs were constructed by replacing $35 \mathrm{~S}$ promoter with promoters of CmCAD1, 2, and 3, respectively, in pCAMBIA1381Z vector. These three genes were chosen according to their positive responses to drought stress [27], phylogenetic analysis [26] and their major functions in lignin synthesis [53]. GUS staining of tabacco leaves after signal molecule treatments obtained similar regulating patterns of the signal molecules to the three $C m C A D$ genes consistent with expression assay, demonstrating $C m C A D$ genes can be regulated by the stress-induced signal molecules similar as Kim et al. (2010) [43] reported. However, CmCAD1 pro::GUS showed the lightest GUS staining and activity either without or with signal molecule treatments, while CmCAD3 pro::GUS exhibited the strongest staining and activity under all conditions and CmCAD2 pro:: GUS the modest. These GUS assays further confirmed the regulations of $\mathrm{ABA}, \mathrm{H}_{2} \mathrm{O}_{2}$ and JA to CmCAD1, 2, and 3 on the one hand and demonstrated that 
CmCAD3 is probably the major lignification member in oriental melon seedlings on the other hand.

\section{Conclusions}

The three signal molecules responded to drought stress strongly, while $\mathrm{ABA}$ and $\mathrm{H}_{2} \mathrm{O}_{2}$ in a fast way. Among the signal molecules, $\mathrm{ABA}$ and $\mathrm{H}_{2} \mathrm{O}_{2}$ showed similar positive regulation patterns to $C m C A D 1,2,3$, and 5, and JA positively regulated $C m C A D 2,3$, and 5 . In addition, these signal molecules also exhibited positive regulations to most of the lignin biosynthesis genes. CAD activity and lignin content are under regulated by the signal molecules, showing positive correlations between lignification and the signal molecules under drought stress. The thereafter promoter::GUS assay provides a further demonstration that the signal molecules function positively in regulating $C m C A D 1,2$, and 3.

\section{Methods}

\section{Plant material and treatments}

Oriental melon (Cucumis melo var. makuwa Makino) cultivar 'CaiHong7' (purchased from Qiqihar Vegetable Research Institution, Qiqihar, Heilongjiang Province, China) was taken as experimental material for lignification related analysis and tobacco (Nicotiana benthamiana) preserved in our lab (the key laboratory of Key Laboratory of Protected Horticulture of Education Ministry and Liaoning Province, Shenyang Agricultural University, Shenyang, China.) was used for promoter analysis. Seeds were sterilized before sowing. Melon seedlings were cultivated using Yamasaki melon nutrient solution (half strength) [54] which was refreshed every 2 days and tobacco seedlings were cultivated in pots (soil: peat: compost $=1: 1: 1)$, both seedlings were cultivated in a growth chamber $\left(25 \pm 2{ }^{\circ} \mathrm{C}, 14 \mathrm{~h} / 10 \mathrm{~h}\right.$ light/dark cycle) in our lab.

Melon seedlings with four fully expended leaves were used for treatments. For drought treatment, PEG-6000 was added to the nutrient solution to the final concentration of $8 \%(\mathrm{w} / \mathrm{v})$; for fluridone (Flu, $\mathrm{ABA}$ inhibitor, $25 \mu \mathrm{M}$ ), imidazol (Imi, $\mathrm{H}_{2} \mathrm{O}_{2}$ scavenger, $10 \mathrm{mM}$ ) [30], or ibuprofen (Ibu, JA inhibitor, $1 \mathrm{mM}$ ) [31] treatment, inhibitor or scavenger were added to the nutrient solution to the intended concentrations; for ABA $(100 \mu \mathrm{M}), \mathrm{H}_{2} \mathrm{O}_{2}$ $(10 \mathrm{mM})$ or MeJA $(100 \mu \mathrm{M})$ treatment, seedlings were sprayed with each configured solution of $\mathrm{ABA}, \mathrm{H}_{2} \mathrm{O}_{2}$ or $\mathrm{MeJA}$; for inhibitor or scavenger combined with drought treatment, seedlings were pretreated with Flu, Imi or Ibu for $12 \mathrm{~h}$ and then transferred to the nutrient solution containing 8\% PEG-6000. Untreated seedlings were taken as control. Samples were collected after treatments at $0 \mathrm{~h}, 1 \mathrm{~h}, 2 \mathrm{~h}, 3 \mathrm{~h}, 5 \mathrm{~h}, 7 \mathrm{~h}, 12 \mathrm{~h}, 1 \mathrm{~d}, 3 \mathrm{~d}, 5 \mathrm{~d}$ for analysis in August 2018 for the first batch and December 2019 for the second batch (voucher No. Cm-20,180,806001 010 and Cm-20,191,212-001 010).

Six-week-old tobacco seedlings were used for agroinfiltration. The inoculated tobacco seedlings were firstly cultivated at room temperature under dark for $24 \mathrm{~h}$, and then at room temperature under light for another $24 \mathrm{~h}$. After preliminary $48 \mathrm{~h}$ cultivation, the tobacco seedlings were then treated with $\mathrm{ABA}(100 \mu \mathrm{M}), \mathrm{H}_{2} \mathrm{O}_{2}(10 \mathrm{mM})$ and MeJA $(100 \mu \mathrm{M})$, respectively. Leaf discs for GUS staining and samples for GUS activity analysis were then collected after $24 \mathrm{~h}$ cultivation at $24{ }^{\circ} \mathrm{C}$ under $16 / 8$ light/ dark condition after treatments in October 2018 for the first batch and January 2020 for the second batch (voucher No. Cm-20,181,013-001 and Cm-20,200,128-001).

Assays of each index contained three biological replicates and each biological replicate included three analytical replicates. The second and third internodes (counted from base to growth point) of treated oriental melon seedlings were collected and used for assays either with fresh or frozen samples. Tobacco leaves for GUS activity assay were collected as frozen samples. Frozen samples were frozen in liquid nitrogen immediately after collection and stored at $-80^{\circ} \mathrm{C}$.

\section{Measurements of $A B A, J A$ and $\mathrm{H}_{2} \mathrm{O}_{2}$ contents}

Contents of $\mathrm{ABA}$ and JA were determined using $0.5 \mathrm{~g}$ frozen samples according to Li et al. (2011) [55] using ELISA assay kit (made by the China Agricultural University). Specific monoclonal antibodies were used for ABA and JA analysis and standard curve was built for each hormone according to the manufacturer instruction. Contents of ABA and JA were expressed as $\mathrm{ng} \mathrm{g}^{-1}$ fresh weight.

Content of $\mathrm{H}_{2} \mathrm{O}_{2}$ was determined using $0.1 \mathrm{~g}$ frozen sample following the manufacturer instruction of $\mathrm{H}_{2} \mathrm{O}_{2}$ content detection kit (Cat\#A064, Nanjing Jiancheng Bioengineering Istitute, Nanjing, China). $\mathrm{H}_{2} \mathrm{O}_{2}$ content was expressed as $\mathrm{mmol} \mathrm{g}^{-1}$ fresh weight (FW) calculated by the absorbance at $405 \mathrm{~nm}$.

\section{Measurement of lignin content}

Lignin contents were measured according to Zhang et al. (2010) [56] as well as we described previously [27, 53]. Extracted lignin solution was measured at $280 \mathrm{~nm}$. Lignin contents were calculated according to a standard curve and expressed as $\mathrm{mg} \mathrm{g}^{-1} \mathrm{DW}$.

\section{Histochemical lignin staining}

The phloroglucinol- $\mathrm{HCl}$ staining was the same as described in our previous study [27]. While, $10 \mu \mathrm{m}$ thickness sections were applied for observation. 


\section{Assay of CAD activity}

CAD activity is performed the same as we described previously [27]. Coniferyl alcohol was used as substrate and CAD activity is presented as $\mathrm{U} \mathrm{mg}^{-1}$ protein. Protein concentration was measured by using BioRad Protein Assay Kit (Code No.T9310A, TaKaRa, Japan) based on the method described by Bradford (1976) [57].

\section{RNA extraction, CDNA synthesis and qRT-PCR}

The processes of RNA extraction, cDNA synthesis and qRT-PCR were executed according to our previous description [27]. The gene sequences of CmPAL1-like, CmPAL2-like, CmCAD1 5, CmPOD1-like, CmPOD2like, CmLAC4-like, CmLAC11-like and CmLAC17-like are achieved in Melonomics (https://www.melonomics. net/), sequences of $18 \mathrm{~s}$ rRNA, CmC4H, Cm4CL1 and CmCOMT are achieved in NCBI (https://www.ncbi.nlm. nih.gov/) and sequence of $C m C C R$ is achieved in PLAZA (https://bioinformatics.psb.ugent.be/plaza/versions/ plaza_v4_dicots/). Gene accession numbers and PCR primer sequences are listed in Table S1. Each-gene/18S rRNA ratio at $0 \mathrm{~h}$ were set to 1 . The $2^{-\Delta \Delta C \mathrm{t}}$ method was used to calculate relative expressions of genes.

\section{Construction of GUS reporter gene vectors and expression in tobacco}

The DNA, used for promoter clone, was extracted from untreated melon leaves using Hi-DNAsecure Plant Kit (Cat\#DP350-02, Tiangen, Beijing, China). PrimeSTAR ${ }^{\circ}$ HS (Premix) (Code No.R040A, TaKaRa, Japan) was used for sequence clone. Promoter sequences of $C m C A D 1$, $C m C A D 2$ and $C m C A D 3$ were firstly cloned using the primers without restriction enzyme cutting site, then added poly-A tails (Cat\#RT124, Tiangen, Beijing, China) and ligated into T-vector (pMDTM19(simple), Code No.3271, TaKaRa, Japan) using T4 DNA ligase kit (Cat\#RT406, Tiangen, Beijing, China) for sequencing. Correct sequences, which are the same with the sequences downloaded from Melonomics (https://www. melonomics.net/), were secondly cloned using the primers with restriction enzyme cutting sites and ligated into linearized pCAMBIA1381Z by using Double Digest Protocol with Acc I and Hind III restriction enzymes. TaKaRa MiniBEST DNA Fragment Purification Kit Ver.4.0 (Code No.9761, TaKaRa, Japan) was used for cloned sequence purification when necessary. The constructed vectors were introduced into Agrobacterium tumefaciens (strain GV3101) competent respectively using freeze-thaw protocol, and the virus was screened and inoculated with $\mathrm{LB}$ medium containing $25 \mathrm{mg} \mathrm{L}^{-1}$ rifampicin and $50 \mathrm{mg} \mathrm{L}^{-1}$ kanamycin. After PCR and gel electrophoresis detection, correct bacterial plaques were inoculated in $50 \mathrm{ml} \mathrm{LB}$ liquid medium in the presence of rifampicin and kanamycin in erlenmeyer flasks for 14-
$16 \mathrm{~h}$. Then, bacterial solutions were centrifuged at $4{ }^{\circ} \mathrm{C}$ $5000 \mathrm{rpm}$ for $10 \mathrm{~min}$. The harvested Agrobacterium pellets were resuspended to the density of 1.0 at $600 \mathrm{~nm}$ in infiltration buffer $\left(10 \mathrm{mM} \mathrm{MgCl}_{2}, 10 \mathrm{mM} \mathrm{MES}, 0.1 \mathrm{mM}\right.$ acetosyringone). After incubation at room temperature under dark condition for $3 \mathrm{~h}$, infiltration cultures were pressure-injected into fully expended leaves of tobacco plants using a $1 \mathrm{ml}$ needleless syringe avoiding veins. Primers used here are listed in Table S2.

\section{GUS staining}

GUS staining in tobacco was assayed according to the method described by Jefferson et al. (1987) [58]. Discs from inoculated tobacco leaves were incubated in GUS staining solution [50 mM phosphate buffer ( $\mathrm{pH} 7.0), 0.5$ $\mathrm{mM} \mathrm{K}_{3} \mathrm{Fe}(\mathrm{CN})_{6}, 0.5 \mathrm{mM} \mathrm{K} \mathrm{K}_{4} \mathrm{Fe}(\mathrm{CN})_{6}, 0.1 \%$ (v/v), Triton $\mathrm{X}-100,10 \mathrm{mM}$ EDTA and $0.5 \mathrm{mg} / \mathrm{ml} \mathrm{X-Gluc} \mathrm{(5-bromo-}$ 4-chloro-3-indolyl- $\beta$-D-glucuronide)] at $37^{\circ} \mathrm{C}$ overnight. The stained samples were then removed chlorophyll with $80 \%(\mathrm{v} / \mathrm{v})$ ethanol and scanned using an Epson scanner (Epson Expression 12000XL).

\section{GUS activity}

GUS activity was referred to the procedures described by Jefferson et al. (1987) [58] and Wang et al. (2019) [59]. Inoculated tobacco leaf $(0.2 \mathrm{~g}$ each biological replicate sample) was used for GUS activity detection which is calculated as $\mu \mathrm{mol}$ of substrates converted to products per minute and expressed as $\mathrm{U} \mathrm{mg}^{-1}$ protein. BioRad Protein Assay Kit was used to determine the protein concentration of enzyme extracts based on the method of coomassie brilliant blue G-250 described by Bradford (1976) [57].

\section{Statistical analysis}

Data were organized using Excel 2013 and analyzed through SPSS 18.0 using Duncan method with $P=0.05$ to test the significance. Then Origin 8.0 and Photoshop CS4 were both used for graph generation and beautification.

\section{Supplementary Information}

The online version contains supplementary material available at https://doi. org/10.1186/s12870-021-02869-y.

Additional file 1 Table S1. Primers used for qRT-PCR analysis.

Additional file $\mathbf{2}$ Table S2. Primers used for promoter clone.

\section{Abbreviations}

CAD: Cinnamyl alcohol dehydrogenase; ABA: Abscisic acid; $\mathrm{H}_{2} \mathrm{O}_{2}$ : Hydrogen peroxide; JA: Jasmonic acid; MeJA: Methyl jasmonic acid; SA: Salicylic acid; ROS: Reactive oxygen species; Flu: Fluridone; Imi: Imidazol; Ibu: Ibuprofen; PEG: Polyethylene glycol; GUS: $\beta$-glucuronidase; qRT-PCR: Quantitative real time polymerase chain reaction; $\mathrm{C} 4 \mathrm{H}$ : Cinnamate 4-hydroxylase; $4 \mathrm{CL}$ : 4coumarate-CoA ligase; CCR: Cinnamoyl-CoA reductase; COMT: Caffeic acid O- 
methyltransferase; PAL: Phenylalanine ammonia lyase; POD: Peroxidase; LAC: Laccase; F5H: Ferulate 5-hydroxylase

\section{Acknowledgements}

We thank Prof. Tao Xu and Prof. Feng Wang for providing valuable assistance in writing this article.

\section{Authors' contributions}

WL, YJ and HYQ conceived and designed the experiments. YZJ identified the lignin biosynthesis genes. WL and $Y J$ performed the experiments. WL, CHW and $J Y$ analyzed the data. WL and YJ wrote the manuscript and HYQ improved it. All authors have read and approved the manuscript.

\section{Funding}

This work was supported by China Agriculture Research System of (CARS-25). The funding body had no role in the design of the experiments and collection, analysis, and interpretation of data and in preparation of the manuscript.

\section{Availability of data and materials}

The data sets are included within the article and its Additional files. Accession numbers of the genes analyzed in this article can be achieved in Table S1.

\section{Ethics approval and consent to participate} Not applicable.

\section{Consent for publication}

Not applicable.

\section{Competing interests}

The authors declare that they have no competing interests.

\section{Author details}

${ }^{1}$ Key Laboratory of Protected Horticulture of Education Ministry and Liaoning Province, College of Horticulture, Shenyang Agricultural University, National \& Local Joint Engineering Research Center of Northern Horticultural Facilities Design \& Application Technology (Liaoning), Shenyang 110866, Liaoning, People's Republic of China. ${ }^{2}$ Vegetable Research Institute, Liaoning Academy of Agricultural Sciences, Shenyang 110161, Liaoning, People's Republic of China. ${ }^{3}$ College of Agriculture, Heilongjiang Bayi Agricultural University, Daqing 163319, Heilongjiang, People's Republic of China. ${ }^{4}$ College of Ecology and Garden Architecture, Dezhou University, Dezhou 253023, People's Republic of China.

\section{Received: 16 April 2020 Accepted: 1 February 2021}

Published online: 08 February 2021

\section{References}

1. Bonawitz ND, Chapple C. The Genetics of Lignin Biosynthesis: Connecting Genotype to Phenotype. Annu Rev Genet. 2010;44(1):337-63.

2. Boudet AM. Lignin and lignification: selected issues. Plant Physiol Biochem 2000;38(1):81-96

3. Srivastava S, Vishwakarma RK, Arafat YA, Gupta SK, Khan BM. Abiotic stress induces change in Cinnamoyl CoA Reductase (CCR) protein abundance and lignin deposition in developing seedlings of Leucaena leucocephala. Physiol Mol Biol Plants. 2015;21(2):197-205.

4. Lee BR, Muneer S, Jung WJ, Avice JC, Ourry A, Kim TH. Mycorrhizal colonization alleviates drought-induced oxidative damage and lignification in the leaves of drought-stressed perennial ryegrass (Lolium perenne). Physiol Plant. 2012;145(3):440-9.

5. Li Z, Peng Y, Ma X. Different response on drought tolerance and postdrought recovery between the small-leafed and the large-leafed white clover (Trifolium repens L.) associated with antioxidative enzyme protection and lignin metabolism. Acta Physiol Plant. 2013;35(1):213-22.

6. Jubany-Marí T, Munné-Bosch S, López-Carbonell M, Alegre L. Hydrogen peroxide is involved in the acclimation of the Mediterranean shrub, Cistus albidus L., to summer drought. J Exp Bot. 2009;60(1):107-20.

7. Dalal M, Sahu S, Tiwari S, Rao AR, Gaikwad K. Transcriptome analysis reveals interplay between hormones, ROS metabolism and cell wall biosynthesis for drought-induced root growth in wheat. Plant Physiol Biochem. 2018;130: 482-92.

8. Yang L, Wang CC, Guo WD, Li XB, Lu M, Yu CL. Differential expression of cell wall related genes in the elongation zone of rice roots under water deficit. Russ J Plant Physiol. 2006;53(3):390-5.

9. Yoshimura K, Masuda A, Kuwano M, Yokota A, Akashi K. Programmed Proteome Response for Drought Avoidance/Tolerance in the Root of a C3 Xerophyte (Wild Watermelon) Under Water Deficits. Plant Cell Physiol. 2008; 49(2):226-41.

10. Voelker SL, Lachenbruch B, Meinzer FC, Kitin P, Strauss SH. Transgenic poplars with reduced lignin show impaired xylem conductivity, growth efficiency and survival. Plant Cell Environ. 2011;34(4):655-68.

11. Hose E, Clarkson DT, Steudle E, Schreiber L, Hartung W. The exodermis: a variable apoplastic barrier. J Exp Bot. 2001;52(365):2245-64

12. Bedon F, Levasseur C, Grima-Pettenati J, Séguin A, MacKay J. Sequence analysis and functional characterization of the promoter of the Picea glauca Cinnamyl Alcohol Dehydrogenase gene in transgenic white spruce plants. Plant Cell Rep. 2009;28(5):787-800.

13. Behr M, Lutts S, Hausman JF, Guerriero G. Jasmonic acid to boost secondary growth in hemp hypocotyl. Planta. 2018;248(4):1029-36.

14. Denness L, McKenna JF, Segonzac C, Wormit A, Madhou P, Bennett M, et al. Cell Wall Damage-Induced Lignin Biosynthesis Is Regulated by a Reactive Oxygen Species- and Jasmonic Acid-Dependent Process in Arabidopsis. Plant Physiol. 2011;156(3):1364.

15. Su G, An Z, Zhang W, Liu Y. Light promotes the synthesis of lignin through the production of $\mathrm{H}_{2} \mathrm{O}_{2}$ mediated by diamine oxidases in soybean hypocotyls. J Plant Physiol. 2005;162(12):1297-303.

16. Kováčik J, Grúz J, Klejdus B, Štork F, Marchiosi R, Ferrarese-Filho O. Lignification and related parameters in copper-exposed Matricaria chamomilla roots: Role of $\mathrm{H}_{2} \mathrm{O}_{2}$ and $\mathrm{NO}$ in this process. Plant Sci. 2010; 179(4):383-9.

17. Mohr PG, Cahill DM. Suppression by ABA of salicylic acid and lignin accumulation and the expression of multiple genes, in Arabidopsis infected with Pseudomonas syringae pv. tomato. Funct Integr Genomic. 2007:7(3): 181-91.

18. Xu W, Tang W, Wang C, Ge L, Sun J, Qi X, et al. SiMYB56 Confers Drought Stress Tolerance in Transgenic Rice by Regulating Lignin Biosynthesis and ABA Signaling Pathway. Front Plant Sci. 2020;11:785.

19. Cheng H, Li L, Xu F, Cheng S, Cao F, Wang Y, et al. Expression patterns of a cinnamyl alcohol dehydrogenase gene involved in lignin biosynthesis and environmental stress in Ginkgo biloba. Mol Biol Rep. 2013;40(1):707-21.

20. Kuyyogsuy A, Deenamo N, Khompatara K, Ekchaweng K, Churngchow N. Chitosan enhances resistance in rubber tree (Hevea brasiliensis), through the induction of abscisic acid (ABA). Physiol Mol Plant Pathol. 2018;102:67-78.

21. Gamuyao R, Nagai K, Ayano M, Mori Y, Minami A, Kojima M, et al. Hormone Distribution and Transcriptome Profiles in Bamboo Shoots Provide Insights on Bamboo Stem Emergence and Growth. Plant Cell Physiol. 2017:58(4):702-16.

22. Yamaguchi $M$, Valliyodan $B$, Zhang J, Lenoble ME, Yu O, Rogers EE, et al. Regulation of growth response to water stress in the soybean primary root. I. Proteomic analysis reveals region-specific regulation of phenylpropanoid metabolism and control of free iron in the elongation zone. Plant Cell Environ. 2010;33(2):223-43.

23. Moura JCMS, Bonine CAV, De Oliveira Fernandes Viana J, Dornelas MC, Mazzafera P. Abiotic and Biotic Stresses and Changes in the Lignin Content and Composition in Plants. J Integr Plant Biol. 2010:52(4):360-76.

24. Barakat A, Bagniewska-Zadworna A, Frost CJ, Carlson JE. Phylogeny and expression profiling of CAD and CAD-like genes in hybrid Populus ( $P$. deltoides $\times P$. nigra): evidence from herbivore damage for subfunctionalization and functional divergence. BMC Plant Biol. 2010;10(1):100.

25. Tobias CM, Chow EK. Structure of the cinnamyl-alcohol dehydrogenase gene family in rice and promoter activity of a member associated with lignification. Planta. 2005;220(5):678-88.

26. Jin Y, Zhang C, Liu W, Qi H, Chen H, Cao S. The Cinnamyl Alcohol Dehydrogenase Gene Family in Melon (Cucumis melo L.): Bioinformatic Analysis and Expression Patterns. PLoS One. 2014;9(7):e101730.

27. Liu W, Jin Y, Li M, Dong L, Guo D, Lu C, et al. Analysis of CmCADs and three lignifying enzymes in oriental melon ('CaiHong7') seedlings in response to three abiotic stresses. Sci Hortic Amsterdam. 2018;237:257-68.

28. Bahrun A, Jensen CR, Asch F, Mogensen VO. Drought-induced changes in xylem $\mathrm{pH}$, ionic composition, and $\mathrm{ABA}$ concentration act as early signals in field-grown maize (Zea mays L.). J Exp Bot. 2002;53(367):251-63. 
29. Riemann M, Dhakarey R, Hazman M, Miro B, Kohli A, Nick P. Exploring Jasmonates in the Hormonal Network of Drought and Salinity Responses. Front Plant Sci. 2015;6:1077.

30. Hu W, Huang C, Deng X, Zhou S, Chen L, Li Y, et al. TaASR1, a transcription factor gene in wheat, confers drought stress tolerance in transgenic tobacco. Plant Cell Environ. 2013;36(8):1449-64.

31. Yang T, Zhu LS, Meng Y, Lv R, Zhou Z, Zhu L, et al. Alpha-momorcharin enhances Tobacco mosaic virus resistance in tobacco ${ }^{\mathrm{NN}}$ by manipulating jasmonic acid-salicylic acid crosstalk. J Plant Physiol. 2018;223:116-26.

32. Jing X, Wang H, Gong B, Liu S, Wei M, Ai X, et al. Secondary and sucrose metabolism regulated by different light quality combinations involved in melon tolerance to powdery mildew. Plant Physiol Biochem. 2018;124:77-87.

33. Berthet $S$, Demont-Caulet N, Pollet B, Bidzinski $P$, Cézard L, Le Bris $P$, et al. Disruption of LACCASE4 and 17 Results in Tissue-Specific Alterations to Lignification of Arabidopsis thaliana Stems. Plant Cell. 2011;23(3):1124-37.

34. Huang J, Gu M, Lai Z, Fan B, Shi K, Zhou YH, et al. Functional Analysis of the Arabidopsis PAL Gene Family in Plant Growth, Development, and Response to Environmental Stress. Plant Physiol. 2010;153(4):1526-38.

35. Tokunaga N, Kaneta T, Sato S, Sato Y. Analysis of expression profiles of three peroxidase genes associated with lignification in Arabidopsis thaliana. Physiol Plant. 2009:136(2):237-49.

36. Kuromori T, Seo M, Shinozaki K. ABA Transport and Plant Water Stress Responses. Trends Plant Sci. 2018;23(6):513-22.

37. Mittler R. ROS Are Good. Trends Plant Sci. 2017;22(1):11-9.

38. Per TS, Khan MIR, Anjum NA, Masood A, Hussain SJ, Khan NA. Jasmonates in plants under abiotic stresses: Crosstalk with other phytohormones matters. Environ Exp Bot. 2018;145:104-20.

39. Zhang C, Huang Z. Effects of endogenous abscisic acid, jasmonic acid, polyamines, and polyamine oxidase activity in tomato seedlings under drought stress. Sci Hortic Amsterdam. 2013;159:172-7.

40. Jang G, Choi YD. Drought stress promotes xylem differentiation by modulating the interaction between cytokinin and jasmonic acid. Plant Signal Behav. 2018;13(3):e1451707.

41. Kojo K, Yaeno T, Kusumi K, Matsumura H, Fujisawa S, Terauchi R, et al. Regulatory Mechanisms of ROI Generation are Affected by Rice spl Mutations. Plant Cell Physiol. 2006;47(8):1035-44.

42. Shan C, Liang Z. Jasmonic acid regulates ascorbate and glutathione metabolism in Agropyron cristatum leaves under water stress. Plant Sci. 2010;178(2):130-9.

43. Kim $\mathrm{YH}$, Bae JM, Huh $\mathrm{GH}$. Transcriptional regulation of the cinnamyl alcohol dehydrogenase gene from sweetpotato in response to plant developmental stage and environmental stress. Plant Cell Rep. 2010;29(7):779-91.

44. Deng WW, Zhang M, Wu JQ, Jiang ZZ, Tang L, Li YY, et al. Molecular cloning, functional analysis of three cinnamyl alcohol dehydrogenase (CAD) genes in the leaves of tea plant, Camellia sinensis. J Plant Physiol. 2013; 170(3):272-82.

45. Seki M, Narusaka M, Ishida J, Nanjo T, Fujita M, Oono Y, et al. Monitoring the expression profiles of 7000 Arabidopsis genes under drought, cold and highsalinity stresses using a full-length cDNA microarray. Plant J. 2002;31(3):279-92.

46. McConn M, Creelman RA, Bell E, Mullet JE, Browse J. Jasmonate is essential for insect defense in Arabidopsis. Proc Natl Acad Sci USA. 1997;94(10):5473-7.

47. Peng $X$, Hu $Y$, Tang $X$, Zhou $P$, Deng $X$, Wang H, et al. Constitutive expression of rice WRKY3O gene increases the endogenous jasmonic acid accumulation, $P R$ gene expression and resistance to fungal pathogens in rice. Planta. 2012;236(5):1485-98.

48. Adie BAT, Pérez-Pérez J, Pérez-Pérez MM, Godoy M, Sánchez-Serrano JJ, Schmelz EA, et al. ABA Is an Essential Signal for Plant Resistance to Pathogens Affecting JA Biosynthesis and the Activation of Defenses in Arabidopsis. Plant Cell. 2007;19(5):1665-81.

49. Lorenzo O, Solano R. Molecular players regulating the jasmonate signalling network. Curr Opin Plant Biol. 2005;8(5):532-40.

50. Carlos dO, Bárbara H, Vicent A, Aurelio GC. Jasmonic acid transient accumulation is needed for abscisic acid increase in citrus roots under drought stress conditions. Physiol Plant. 2013;147(3):296-306.

51. Hu Q, Min L, Yang X, Jin S, Zhang L, Li Y, et al. Laccase GhLac1 Modulates Broad-Spectrum Biotic Stress Tolerance via Manipulating Phenylpropanoid Pathway and Jasmonic Acid Synthesis. Plant Physiol. 2018;176(2):1808.

52. Alamgir Hossain M, Zakir Hossain AKM, Kihara T, Koyama H, Hara T. Aluminum-Induced Lipid Peroxidation and Lignin Deposition Are Associated with an Increase in $\mathrm{H}_{2} \mathrm{O}_{2}$ Generation in Wheat Seedlings. Soil Sci Plant Nutr. 2005;51(2):223-30.
53. Liu W, Jiang $Y$, Wang C, Zhao L, Jin $Y$, Xing Q, et al. Lignin synthesized by CmCAD2 and CmCAD3 in oriental melon (Cucumis melo L.) seedlings contributes to drought tolerance. Plant Mol Biol. 2020;103(6):689-704.

54. Liu S. Modern practical soilless cultivation technique. Beijing (in Chinese): China Agriculture Press; 2001.

55. Li Y, Zhao H, Duan B, Korpelainen $H$, Li C. Effect of drought and ABA on growth, photosynthesis and antioxidant system of Cotinus coggygria seedlings under two cdhfjgfjcgdifferent light conditions. Environ Exp Bot. 2011;71(1):107-13.

56. Zhang L, Wang G, Chang J, Liu J, Cai J, Rao X, et al. Effects of 1-MCP and ethylene on expression of three CAD genes and lignification in stems of harvested Tsai Tai (Brassica chinensis). Food Chem. 2010;123(1):32-40.

57. Bradford MM. A rapid and sensitive method for the quantitation of microgram quantities of protein utilizing the principle of protein-dye binding. Anal Biochem. 1976;72(1):248-54.

58. Jefferson RA, Kavanagh TA, Bevan MW. GUS fusions: beta-glucuronidase as a sensitive and versatile gene fusion marker in higher plants. EMBO J. 1987; 6(13):3901-7.

59. Wang C, Gao G, Cao S, Xie Q, Qi H. Isolation and functional validation of the CmLOX08 promoter associated with signalling molecule and abiotic stress responses in oriental melon, Cucumis melo var. makuwa Makino. BMC Plant Biol. 2019;19(1):75

\section{Publisher's Note}

Springer Nature remains neutral with regard to jurisdictional claims in published maps and institutional affiliations.
Ready to submit your research? Choose BMC and benefit from:

- fast, convenient online submission

- thorough peer review by experienced researchers in your field

- rapid publication on acceptance

- support for research data, including large and complex data types

- gold Open Access which fosters wider collaboration and increased citations

- maximum visibility for your research: over $100 \mathrm{M}$ website views per year

At BMC, research is always in progress.

Learn more biomedcentral.com/submissions 